\title{
Evolution of Affective Career Outcomes: A Field Study of Academic Librarians
}

\section{Joyce S. Phillips, Kerry D. Carson, and Paula P. Carson}

\begin{abstract}
One hundred nine master-level librarians of varying ages were surveyed about their career attitudes. Hierarchial polynomial regression was then employed to examine the relationships between age and three affective outcomes: (1) career satisfaction, (2) career entrapment, and (3) career identity. Results indicated the age-satisfaction relationship was linear, demonstrating that librarians become increasingly pleased with their profession over time. A similar linear relationship between age and entrapment indicated that as librarians mature, they become bound to their line of work because of accumulated investments and decreased career options. The relationship between age and identity assumed a curvilinear, or inverted $U$-shaped form. Career identity was higher at mid-career and lower at both early and late career stages. Implications of these findings are advanced.
\end{abstract}

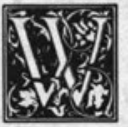

hen trained individuals accept positions in libraries, they do more than gain employment-they embark upon their careers. How they manage their careers not only affects their personal wellbeing but also influences organizational effectiveness. Yet the process of career progression virtually has been ignored in librarianship literature. Such a lack of research is surprising given that the systematic and comprehensive study of careers may assist library administrators in understanding effective vocational development. ${ }^{1}$

Career management literature suggests that professionals such as librarians traditionally pass through specific career stages over their work life. ${ }^{2}$ Gen- erally, librarians struggle to fit into their chosen profession during the early career stage. By midcareer, they have mastered many of the intricacies of their vocation. And by late career they begin to prepare for retirement, disengaging themselves from the occupation. ${ }^{3}$ Figure 1 summarizes the behaviors and attitudes associated with each of these career stages. Additionally, the figure identifies the prototypical ages during which professionals pass through each stage.

The purpose of the present study is to investigate how attitudes toward the profession evolve as librarians age and pass through these progressive career stages. To derive justifiable predictions about the relationship between age and affective career outcomes, hypotheses

Joyce S. Phillips is Serials/ILL Librarian at W. B. Roberts Library, Delta State University, Kerry D. Carson is Assistant Professor, and Paula P. Carson is Assistant Professor in the Department of Management and Marketing at Texas A\&M University, Corpus Christi, Texas 78412. The helpful comments of Connie Van Fleet on an earlier manuscript are gratefully acknowledged. An earlier version of this paper was presented at the Academy of Business Administration 1994 National Conference, Las Vegas, Nevada. 


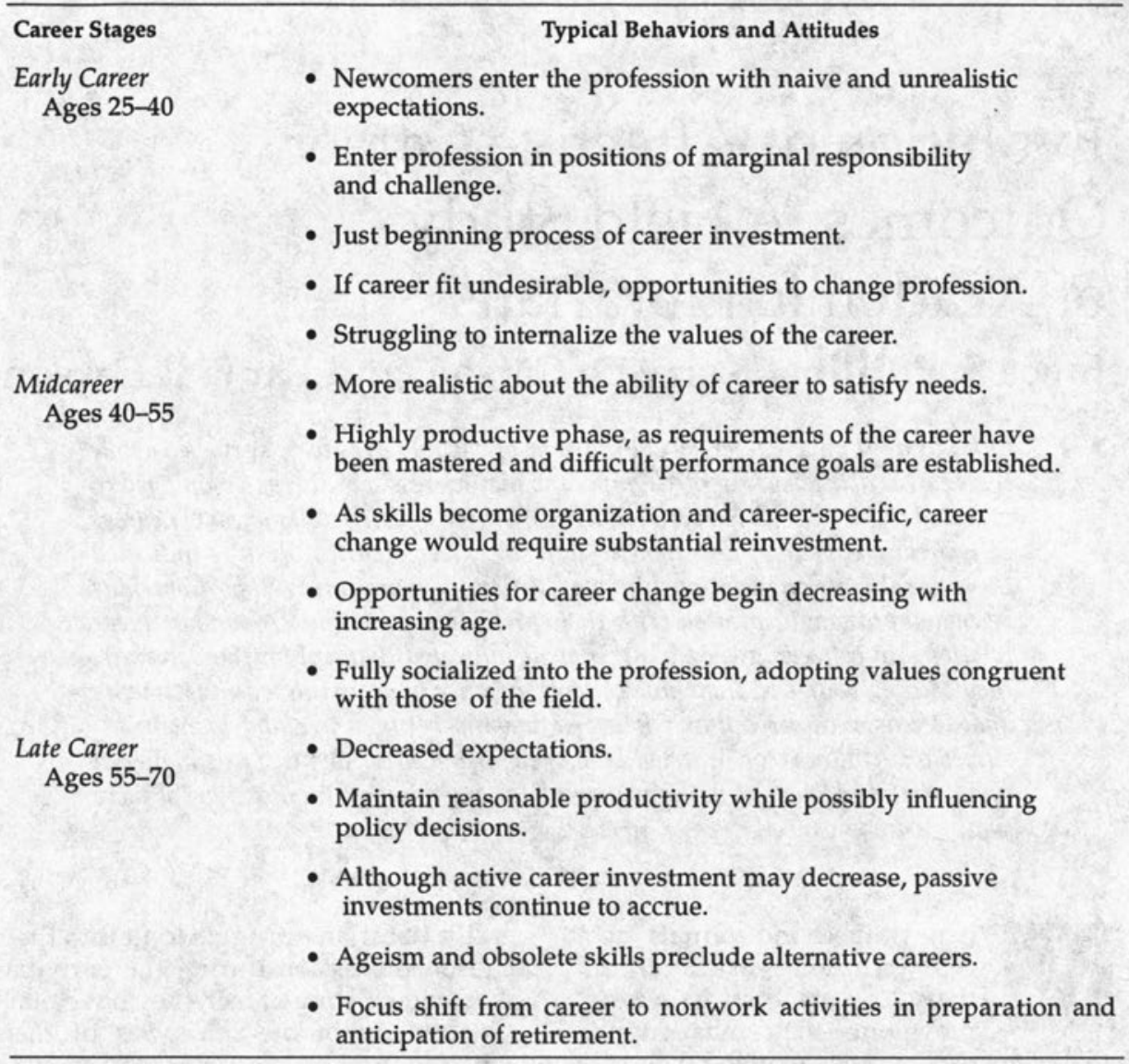

\section{FIGURE 1}

Career Stages and Associated Behaviors/Attitudes

were formulated based on career stage theory. ${ }^{4}$ Career stage theory implies an "ontogenesis" perspective which assumes that human attitudes change regularly throughout the life span in a predictable fashion. ${ }^{5}$

\section{HYPOTHESIS DEVELOPMENT}

As individuals graduate from library education programs and enter the vocation of librarianship, they often bring with them naive and unrealistic expectations about the world of work. ${ }^{6}$ Newcomers to the field are often overly ambitious and idealistic about their ability to influence the functioning of the library. Instead of assuming positions involving substantial discretion, new hires are often assigned repetitive job duties, lacking opportunity for creative initiatives. " The "reality shock" associated with initial expectations being unrealized often induces high levels of frustration and disappointment. ${ }^{8}$ Thus, newcomers predictably report low levels of satisfaction.

By midcareer, however, librarians are likely to advance from entry-level positions to those of increased responsibility and authority. Such enriched jobs are both more fulfilling and satisfying. ${ }^{9}$ By late career, librarians are likely to assume those positions most instrumental in influencing the direction of the library and their profession. Those not choosing to move up the traditional administrative 
hierarchy will likely use their expertise to influence junior colleagues through mentoring relationships. These growth opportunities induce even higher satisfaction with the career. ${ }^{10}$

\section{Hypothesis \#1: As Librarians Age, Career Satisfaction Will Linearly Increase.}

Though late career librarians may express high levels of occupational satisfaction, this positive effect may be partially attributable to rationalization. ${ }^{11}$ Aging librarians may cognitively distort any misgivings about the profession because they are entrapped in their careers. Career entrapment reflects the degree to which individuals remain in a field because of the high costs of withdrawal and the lack of available career alternatives. ${ }^{12}$

Successful entry into a new occupation requires that newcomers adapt their values to be congruent with those of the vocation.

Career changers risk forfeiting investments in time, money, and effort associated with obtaining educational credentials and career-specific skills. ${ }^{13}$ Besides these economic investments, individuals typically develop emotional attachments and obligations that increase the cost of career change. ${ }^{14} \mathrm{Re}$ source allocation and preserving emotional stakes divert individual energies from scanning the environment for viable career alternatives. ${ }^{15}$ As external stimuli are ignored, career opportunities pass unnoticed. Individuals experience a constriction in their perception of career options. Such tunnel vision obfuscates opportunities until, with the passage of time, alternatives diminish. ${ }^{16}$

\section{Hypothesis \#2: As Librarians Age, Career Entrapment Will Linearly Increase.}

Those who are entrapped remain in their career field because of accumulated investments that would be lost if they voluntarily changed professions. However, those who become committed to the librarianship field because of psychological attachments remain loyal because they identify with the goals and values of the vocation. Their career identity reflects an emotional attachment to the profession.

In the early career stage, librarians have not yet been fully socialized into the vocation. Successful entry into a new occupation requires that newcomers adapt their values to be congruent with those of the vocation. During this period of psychological readjustment, librarians display increasing emotional attachment to the profession. Identity peaks in mid-career as librarians become involved in more meaningful and challenging tasks. ${ }^{17}$ However, as librarians prepare for eventual withdrawal from the career field, they begin to emotionally disengage from their profession turning instead toward family and nonwork activities.

\section{Hypothesis \#3: The Relationship between Age and Career Identity Will Be Curvilinear.}

If librarians in late career tend toward emotional detachment from the job, it is predicted that the relationship between age and career identity will be curvilinear, shaped in the form of an inverted $U$. As workers deviate from the highly productive middle phase of their careers, they will become less involved and less attached to the values of their profession. In early career, adapting to and becoming socialized into an unfamiliar occupation preclude high levels of identity. In late career, previously high levels of identity wane as librarians disengage in anticipation of retirement.

\section{METHOD \\ Sample and Procedure}

The initial sample consisted of 137 members of the academic section of a southeastern state library association (response rate $=66.5$ percent). Of these respondents, only the 109 with master's degrees were retained for the final sample (about 80 percent female; just over 59 percent married). Association members were surveyed by mail and received a follow-up postcard reminding them to 
complete the survey two weeks after the initial mailing. Surveys were accompanied by a cover letter assuring confidentiality. The following prefatory instructions introduced the first section of the survey: "This survey begins with statements about your LINE OF WORK or CAREER FIELD in which you are currently employed. You may consider line of work/career field as having the same meaning as occupation, profession, or vocation." Following the line of work/career field items, the surveys requested demographic-related information including marital status, chronological age, gender, position tenure, and educational level.

\section{Measures}

A five-point-rating scale was used to measure career responses ( 1 = strongly disagree to 5 = strongly agree). Items used in the career measures are provided in appendix $A$.

Career Satisfaction. A five-item career satisfaction measure (alpha coefficient $=.76$ ), adapted from the psychometrically sound job satisfaction index developed by Brayfield and Rothe, was used to assess enjoyment with one's line of work. ${ }^{18}$

Career Entrapment. Career entrapment (alpha coefficient $=.86$ ) was tapped with a twelve-item measure of adequate reliability and construct validity. ${ }^{19}$

Career Identity. Career identity was gauged using a four-item measure (alpha coefficient $=.79$ ) that has satisfactory psychometric properties. ${ }^{20}$

\section{Data Analyses}

Because the hypotheses suggest that the relationships between age and career attitudes could assume either a linear or a curvilinear form, hierarchial polynomial regression analysis was performed. To reduce possible confounding resulting from the established relationship between time-related and attitudinal variables, position tenure was controlled by entering it in the first step of each equation. ${ }^{21}$ For each equation, age was entered in the second step, followed by the age ${ }^{2}$ term (age $X$ age) in the third step, and the age $^{3}$ term (age $X$ age $X$ age) in the fourth step. If linearity best describes the form of the relationship, the age term alone should explain a significant portion of the criterion variance while the higher order terms should not. If the relationship is curvilinear or Ushaped, the age $\mathrm{e}^{2}$ term should explain a significant portion of the variance beyond the age term. Finally, if the relationship is S-shaped, the age $^{3}$ term should be significant. ${ }^{2}$

\section{RESULTS}

Table 1 presents a triangular disclosure matrix including the career attitude variables as well as position tenure, age and age ${ }^{2}$. The table also includes means and standard deviations for each variable, and reliability estimates where appropriate. The age $\mathrm{e}^{3}$ variable did not enter into any of the regression equations, so it was excluded from the correlation matrix.

TABLE 1

TRIANGULAR DISCLOSURE MATRIX FOR ALL STUDY VARIABLES

\begin{tabular}{lrrcccccc}
\hline Variable & \multicolumn{1}{c}{ M } & \multicolumn{1}{c}{ S.D. } & \multicolumn{1}{c}{1} & \multicolumn{1}{c}{2} & 3 & 4 & 5 & 6 \\
\hline 1. Age & 44.16 & 9.40 & (NA) & & & & & \\
2. Age & $22,037.09$ & 851.13 & .99 & (NA) & & & & \\
3. Position & & & & & & & & \\
$\quad \begin{array}{l}\text { Tenure (mos.) } \\
\text { 4. Career identity }\end{array}$ & 76.17 & 84.35 & .34 & .36 & $(\mathrm{NA})$ & & & \\
5. Career & 4.06 & .67 & .15 & .13 & .09 & $(.79)$ & & \\
$\quad$ satisfaction & 4.23 & .46 & .22 & .22 & -.05 & .28 & $(.76)$ & \\
6. Career & & & & & & & & \\
entrapment & 2.84 & .63 & .25 & .25 & .08 & .24 & -.01 & $(.86)$ \\
\hline
\end{tabular}

Note: $n=109$. For $r>+.21, p<.05$; for $r>+.26, p<.01$, both two-tailed. Reliability estimates are in the diagonal. 
Table 2 presents the results of the regression analyses controlling for position tenure. As can be detected from this table, the relationships between age and career satisfaction and age and career entrapment were linear. The relationship between age and career identity was curvilinear, as the age $^{2}$ term entered into the equation. Thus, all three hypotheses were supported.

Each of the three equations is plotted in figure 2. This figure reveals that career identity peaks when librarians approach the midcentury mark. Both

TABLE 2

HIERARCHIAL POLYNOMIAL REGRESSION RESULTS FOR AGE AND CAREER VARIABLES, CONTROLLING FOR POSITION TENURE

\begin{tabular}{lcccc}
\hline Dependent Variables & Beta & $R^{2}$ & Change in $R^{2}$ & Fstep \\
\hline Career identity & & & & \\
Position tenure & .09 & .01 & .01 & $<1$ \\
Age & 1.67 & .02 & .01 & 1.7 \\
Age $^{2}$ & -1.57 & .06 & .04 & $3.6^{*}$ \\
Career satisfaction & & & & \\
Position tenure & -.17 & .01 & .01 & $<1$ \\
Age & .18 & .07 & .06 & $7.5^{* *}$ \\
Age & .12 & .07 & .00 & $<1$ \\
Career entrapment & & & & \\
Position tenure & -.03 & .01 & .01 & $<1$ \\
Age $^{2}$ & .08 & .06 & .05 & $6.6^{* *}$ \\
Age $^{2}$ & .19 & .07 & .01 & $<1$ \\
\hline
\end{tabular}

${ }^{*} \mathrm{p}<.05 ;{ }^{* *} \mathrm{p}<.01$
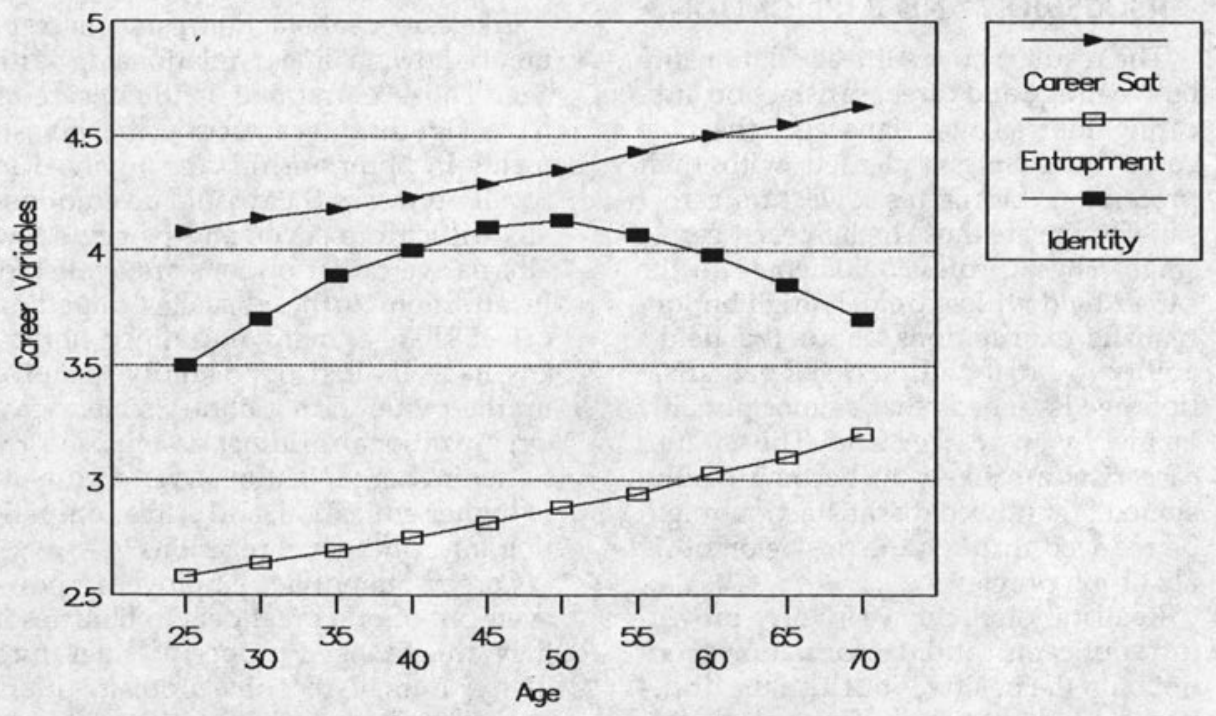

FIGURE 2

Plotted Regression Equations: Career Variables and Age 
career satisfaction and career entrapment increase steadily throughout the librarians' working years.

The results of this study should be considered in light of some limitations. First, the form of the relationships between age and career attitudes may be affected by the composition of the sample. The same analyses using different occupational groups may reveal differently shaped regression curves. Second, the data analyzed were collected crosssectionally rather than longitudinally. Data collected over librarians' life spans may reveal additional insights-particularly when those librarians follow atypical career patterns. In addition, it should be recognized that results from those in late career might be biased due to a self-selection effect; that is, those who are career dissatisfied may have already changed fields at a younger age. Lastly, future researchers may wish to expand our sample by surveying librarians in nonacademic settings as well as those in other geographical regions, as members of the present sample all resided in a single southern state.

\section{DISCUSSION AND IMPLICATIONS}

The results show a linear relationship between age and career satisfaction indicating that as librarians age, they become increasingly pleased with their profession. Librarians lowest on career satisfaction are those in their early career stage. These professionals come to the career field with extremely high but unrealistic expectations about the field's ability to satisfy all their self-actualization needs-needs that cannot possibly be met by any career field. Thus, junior careerists are likely to become disillusioned. Yet novice dissatisfaction might be reduced through the provision of realistic job previews.

Realistic job previews involve providing applicants candid information about not only the positives but also the drawbacks of a position. These previews serve to lower initial expectations to realistic levels, which increases satisfaction and ultimately reduces voluntary withdrawal. ${ }^{23}$ Realistic job previews are typically provided by either interviewers or coworkers. But as technology advances, future researchers might investigate whether realistic job previews can be communicated effectively through interactive computing or videotapes-media thoroughly familiar to academic librarians.

Unlike those in the early career stage who initially may be placed in impoverished positions, midcareer librarians are often challenged by their jobs. But overchallenge may be burdening and overwhelming. Motivation theory posits that difficult goals can stimulate increased levels of productivity. However, these goals may create dissatisfaction because they are often unattainable and seldom realized. Administrators can help the overchallenged mid-career librarian by: (1) establishing moderate goals rather than difficult ones; (2) setting two goals, one that is fully achievable and another that is ideal; (3) recognizing partial success toward meeting difficult goals; (4) incrementally raising goal difficulty; and (5) defining goal difficulty, not in terms of success probability, but by time and effort requirements. ${ }^{24}$

Like career satisfaction, career entrapment shows a linear relationship with age. Those entrapped in their careers have significant career-specific investments in librarianship, are involved in social networks that would be emotionally difficult to sever, and perceive few alternative career options are available. In addition to the obstacles impeding career change, many entrapped librarians have limited opportunity to move up the pyramid in a library's hierarchy. Organizational gridlock is imposed by flattening organizations, retrenchment in higher education, and fierce competition for upper-level positions. ${ }^{25}$

Career immobile employees, however, can offer a great deal to libraries if they are managed properly. ${ }^{26}$ Literature in the human resource domain offers suggestions for dealing with employees who have stagnated in their careers and lost motivation for self-development. ${ }^{27}$ Recommendations include providing 
opportunities for involvement in special projects, permitting job rotation, facilitating downward, lateral or cross-functional moves, and allowing temporary reassignments. Other, less traditional guidance includes encouraging a "psychological success" culture, avoiding a paternalistic orientation to career development in which the individual abdicates responsibility, advocating shortrather than long-term planning, facilitating lifelong learning, sanctioning more diverse career paths, and focusing on accomplishment rather than only on potential. ${ }^{28}$ Such career management techniques may satisfy needs and eliminate potential negative consequences, such as deterioration in morale and decrements in performance. ${ }^{29}$

Demographic analysis suggests that over the coming decades it will be more difficult to recruit new qualified librarians, while those currently employed will become increasingly entrapped.

While career entrapment and career satisfaction show a linear relationship with age, career identity displays an inverted U pattern. That is, career identity is optimal at the midcareer stage, but suboptimal in early and late career stages. To increase early career identity, librarians can be encouraged to become involved in professional associations. In late career, identity can be increased by encouraging mentoring. Typically, men- tors serve outside the formal reward structures while promoting the careers of their protégés. ${ }^{30}$ While developmental benefits accrue to the protégé, mentoring can also benefit the organization as well as the mentor. Serving as a mentor for a less experienced colleague can effectively enhance feelings of self-efficacy. And such interpersonal relationships may help meet affiliation needs, thereby reducing dysfunctional stress. ${ }^{31}$

As environmental pressures are forcing academic library restructuring and placing heightened importance on accountability, it is becoming increasingly important to effectively manage librarians of all ages. Demographic analysis suggests that over the coming decades it will be more difficult to recruit new qualified librarians, while those currently employed will become increasingly entrapped. Therefore, the management of career development is becoming a paramount supervisory skill.

Notably, career development influences both individuals and the libraries in which their professions unfold. Librarians dissatisfied with career progression may turn into organizational liabilities either through substandard performance or through withdrawal behaviors. In contrast, successful career management fosters personal productivity and workplace commitment. This research begins shedding some light on responses to career stagnation and dissatisfaction and offers strategies for effective career development. Further examination of these issues may offer even more insight.

\section{REFERENCES AND NOTES}

1. Glenn R. Carroll, Heather A. Haveman, and Anand Swaminathan, "Careers in Organizations: An Ecological Perspective," Life-Span Development and Behavior 11(1992): 111-44.

2. Jeffrey H. Greenhaus, Career Management (Hinsdale, Ill.: Dryden Pr., 1987).

3. K. Michele Kacmar and Gerald R. Ferris, "Theoretical and Methodological Considerations in the Age-Job Satisfaction Relationship," Journal of Applied Psychology 74 (Apr. 1989): 201-7.

4. Ibid.

5. Gerald Zeitz, "Age and Work Satisfaction in a Government Agency: A Situational Perspective," Human Relations 43 (May 1990): 419-38.

6. Daniel Charles Feldman, "The Multiple Socialization of Organization Members," Academy of Management Review 6 (Apr. 1981):309-18. 
7. Jan S. Squire, "Job Satisfaction and the Ethnic Minority Librarian," Library Administration \& Management 5 (Fall 1991): 194-203.

8. Everett C. Hughes, Men and their Work (Glencoe, Ill.: Free Press, 1958).

9. Beverly P. Lynch and Jo Ann Verdin, "Job Satisfaction in Libraries: Relationships of the Work Itself, Age, Sex, Occupational Group, Tenure, Supervisory Level, Career Commitment and Library Department," Library Quarterly 53 (Oct. 1983): 434-47.

10. Arvid J. Bloom and Christine W. McCawley, "Job Satisfaction in the Library Profession: Results and Implications from a Pennsylvania Survey," Library Administration \& Management 7 (Spring 1993): 89-93.

11. Timothy A. Judge and Edwin A. Locke, "Effect of Dysfunctional Thought Processes on Subjective Well-Being and Job Satisfaction," Journal of Applied Psychology 78 (June 1993): 475-90.

12. Kerry D. Carson, Paula Phillips Carson, and Arthur G. Bedeian, "Development and Construct Validation of a Career Entrapment Measure," (manuscript under review).

13. Douglas T. Hall, "Breaking Career Routines: Midcareer Choice and Identity Development," in Career Development in Organizations, ed. Douglas T. Hall and Associates (San Francisco: Jossey-Bass, 1986).

14. Samuel D. Osherson, Holding On or Letting Go: Men and Career Change at Midlife (New York: Free Press, 1980).

15. Allan I. Teger, Too Much Invested to Quit: The Psychology of Escalation of Conflict (Tarrytown, N.Y.: Pergamon, 1980).

16. Joel Brockner and Jeffrey Z. Rubin, Entrapment in Escalating Conflicts: A Social Psychological Analysis (New York: Springer Pub., 1985).

17. Cary Chernis, "Career Commitment in Human Service Professionals: A Biographical Study," Human Relations 44 (May 1981): 419-37.

18. Arthur H. Brayfield and Harold F. Rothe, "An Index of Job Satisfaction," Journal of Applied Psychology 35 (Oct. 1951): 307-11.

19. Carson, Carson, and Bedeian, "Development and Construct Validation of a Career Entrapment Measure," (manuscript under review).

20. Kerry D. Carson and Arthur G. Bedeian, "Career Commitment: Construction of a Measure and Examination of Its Psychometric Properties," Journal of Vocational Behavior (in press).

21. Fred Luthans and Linda Thomas, "The Relationship between Age and Job Satisfaction: Curvilinear Results from an Empirical Study," Personnel Review 18 (1989):23-26.

22. Kacmar and Ferris, "Theoretical and Methodological Considerations," 201-7.

23. Augustine O. Agho, Charles W. Mueller, and James L. Price, "Determinants of Employee Job Satisfaction: An Empirical Test of a Causal Model," Human Relations 46 (Aug. 1993): 1007-27.

24. Edwin A. Locke, and Gary P. Latham, "Work Motivation and Satisfaction: Light at the End of the Tunnel," Psychological Science 1(July 1990): 240-46.

25. Barbara A. DeLon, "Keeping Plateaued Performers Motivated," Library Administration \& Management 7 (Winter 1993): 13-16.

26. Ibid.

27. Douglas T. Hall and S. Rabinowitz, "Maintaining Employee Involvement in a Plateaued Career," in Career Growth and Human Resource Strategies, ed. Manuel London and Edward M. Mone (New York: Quorum Books, 1988): 67-80.

28. Douglas T. Hall and Judith Richter, "Career Gridlock: Baby Boomers Hit the Wall," Academy of Management Executive 4 (Aug. 1990): 7-22.

29. John P. Meyer, Sampo V. Paunonen, Ian R. Gellatly, Richard D. Goffin, and Douglas N. Jackson, "Organizational Commitment and Job Performance: Its the Nature of the Commitment That Counts," Journal of Applied Psychology 74 (Feb. 1989): 152-56.

30. Kathy E. Kram, "Phases of the Mentor Relationship," Academy of Management Journal 26 (Dec. 1983): 608-25.

31. Kathy E. Kram and Douglas T. Hall, "Mentoring as an Antidote to Stress during Corporate Trauma," Human Resource Management 28 (Winter 1989): 493-510. 


\section{APPENDIX A}

\section{Career Satisfaction Items}

- My line of work/career field is usually interesting enough to keep me from getting bored.

- I am often bored with my line of work/career field.

- I feel fairly satisfied with my present line of work/career field.

- My line of work/career field is pretty uninteresting.

- I find real enjoyment in my line of work/career field.

\section{Career Entrapment Items}

- I have too much time invested in my line of work/career field to change.

- If I left this line of work/career field, I would feel like I had no reasonable options.

- There would be a great emotional price involved in changing my line of work/career field.

- Given my experience and background, there are attractive alternatives available to me in other lines of work/career fields.

- Changing my line of work/career field would be easy from an emotional standpoint.

- I would have many options if I decided to change my line of work/career field.

- It would be very costly for me to switch my line of work/career field.

- Leaving my line of work/career field would cause little emotional trauma in my life.

- I am pleased that I have many alternatives available for changing my line of work/career field.

- For me to enter another line of work/career field would mean giving up a substantial investment in training.

- It would be emotionally difficult to change my line of work/career field.

- I have too much money invested in my line of work/career field to change at this time.

\section{Career Identity Items}

- My line of work/career field is an important part of who I am.

- This line of work/career field has a great deal of personal meaning to me.

- I do not feel "emotionally attached" to this line of work/career field.

- I strongly identify with my chosen line of work/career field. 